\title{
Micromagnetic Characterization of Operation-Induced Damage in Charpy Specimens of RPV Steels
}

\author{
Madalina Rabung ${ }^{1, *(\mathbb{D}}$, Melanie Kopp ${ }^{1}$, Antal Gasparics $\left.{ }^{2}{ }^{(}\right)$, Gábor Vértesy ${ }^{2} \mathbb{( D}$, Ildikó Szenthe ${ }^{2}$, \\ Inge Uytdenhouwen ${ }^{3}$ and Klaus Szielasko ${ }^{1}$ \\ 1 Fraunhofer Institute for Nondestructive Testing (IZFP), 66123 Saarbrücken, Germany; \\ melanie.kopp@izfp.fraunhofer.de (M.K.); klaus.szielasko@izfp.fraunhofer.de (K.S.) \\ 2 Centre for Energy Research, 1121 Budapest, Hungary; gasparics.antal@energia.mta.hu (A.G.) \\ vertesy.gabor@energia.mta.hu (G.V.); szenthe.ildiko@energia.mta.hu (I.S.) \\ 3 SCK CEN Belgian Nuclear Research Centre, 2400 Mol, Belgium; inge.uytdenhouwen@sckcen.be \\ * Correspondence: madalina.rabung@izfp.fraunhofer.de; Tel.: +49-(0)681-9302-3882
}

check for

updates

Citation: Rabung, M.; Kopp, M.; Gasparics, A.; Vértesy, G.; Szenthe, I.; Uytdenhouwen, I.; Szielasko, K. Micromagnetic Characterization of Operation-Induced Damage in Charpy Specimens of RPV Steels. Appl. Sci. 2021, 11, 2917. https:// doi.org/10.3390/app11072917

Academic Editors: Jinyi Lee and Hoyong Lee

Received: 29 January 2021

Accepted: 20 March 2021

Published: 24 March 2021

Publisher's Note: MDPI stays neutral with regard to jurisdictional claims in published maps and institutional affiliations.

Copyright: (c) 2021 by the authors. Licensee MDPI, Basel, Switzerland. This article is an open access article distributed under the terms and conditions of the Creative Commons Attribution (CC BY) license (https:// creativecommons.org/licenses/by/ $4.0 /)$.
Featured Application: In this study, the influence of neutron irradiation on the mechanical properties of nuclear pressure vessel materials is investigated using two independent methods of nondestructive magnetic testing. A correlation was found between magnetic characteristics and neutron irradiation-induced damage, regardless of the applied measurement technique. Additionally, by merging the outcome of both testing methods and applying a calibration/training procedure, the damage to reactor steel was successfully predicted. The results are helpful for the potential future practical application of these techniques to the regular inspection of nuclear reactors.

Abstract: The embrittlement of two types of nuclear pressure vessel steel, 15Kh2NMFA and A508 Cl.2, was studied using two different methods of magnetic nondestructive testing: micromagnetic multiparameter microstructure and stress analysis (3MA-X8) and magnetic adaptive testing (MAT). The microstructure and mechanical properties of reactor pressure vessel (RPV) materials are modified due to neutron irradiation; this material degradation can be characterized using magnetic methods. For the first time, the progressive change in material properties due to neutron irradiation was investigated on the same specimens, before and after neutron irradiation. A correlation was found between magnetic characteristics and neutron-irradiation-induced damage, regardless of the type of material or the applied measurement technique. The results of the individual micromagnetic measurements proved their suitability for characterizing the degradation of RPV steel caused by simulated operating conditions. A calibration/training procedure was applied on the merged outcome of both testing methods, producing excellent results in predicting transition temperature, yield strength, and mechanical hardness for both materials.

Keywords: neutron irradiation embrittlement; reactor pressure vessel; magnetic nondestructive evaluation; micromagnetic multiparameter microstructure and stress analysis 3MA; magnetic adaptive testing

\section{Introduction}

The safe operational lifetime of reactor pressure vessels depends on a number of factors, including design, chemical composition, microstructure, and mechanical characteristics of the reactor pressure vessel (RPV) steels and their in-service-induced change in properties, defect occurrence, and tolerance, as well as operating conditions. Regarding defects, their nature, location, size, density, and growth rate also need to be considered. Operation conditions that affect operational lifetime are neutron exposure (fluence), operation temperature, and the number and magnitude of temperature/pressure cycles in 
normal conditions and hypothetical accidental conditions. During their operation, RPVs are prone to neutron-irradiation-induced embrittlement.

Currently, progressive material degradation is assessed using destructive tests performed on surveillance specimens in the frame of periodic safety reviews (PSRs). These are standard tensile specimens and ISO-V Charpy specimens of exactly the same RPV steels and their welds. Charpy impact tests are systematically used to assess structural materials over a long period [1]. The impact energy is recorded as a function of the temperature, where the temperature corresponding to an impact energy index value of $41 \mathrm{~J}$, representing the ductile to brittle transition temperature (DBTT), and upper shelf energy (USE), representing fully ductile behavior, are determined. To obtain a single DBTT value, several specimens must be tested. In parallel, tensile specimens tested under a quasistatic loading rate are used to determine yield strength, tensile strength, uniform elongation, total elongation, and reduction in diameter. The disadvantage of destructive methods is that they do not allow for the characterization of the progress of material properties of the same specimen when successively damaged, and they are not applicable to the actual component.

In this context, the development of nondestructive evaluation (NDE) technologies can significantly contribute to the characterization of embrittlement in reactor pressure vessel (RPV) materials by providing complementary information about the progress of material properties. Tests performed nondestructively, in general, do not directly determine the material properties, which are determined by destructive tests. To quantify the material properties nondestructively, nondestructive methods must be correlated with the standardized data measured destructively.

Numerous nondestructive methods are suitable for the characterization of operationinduced damage to RPVs: measurement of the Seebeck coefficient [2,3], ultrasonic techniques [4-6], magnetic testing methods [7-12], and magnetoacoustic emission [13].

In ferromagnetic materials, the correlation between mechanical and magnetic hardness is well-known and understood [14,15]. Magnetic methods are advantageous because they are technically simple, inexpensive, and can be applied easily, even on active materials in hot cells.

A micromagnetic nondestructive method that is basically suitable for the characterization of damage to ferromagnetic materials such as RPV steel and for monitoring the progress of material properties is the micromagnetic multiparameter microstructure and stress analysis (3MA) approach, which uses several methods [16-18]. In this study, we applied a new version of the 3MA technique, 3MA-X8 [19]. This technique is presented in more detail in Section 2.2. This novel method offers improved sensitivity and reliability compared with the previous implementation of the 3MA method.

Another promising candidate for magnetic nondestructive testing methods is based on the detection of minor magnetic hysteresis loops. The philosophy behind this technique is that by measuring minor loops instead of major hysteresis loops, the sensitivity and reliability of the measurement can be significantly improved $[20,21]$. Similar to 3MA$\mathrm{X} 8$, magnetic adaptive testing (MAT) is also a multiparametric, powerful, and sensitive procedure for magnetic inspection [22,23].

The purpose of this work is to analyze parameters derived from the 3MA-X8 and MAT methods separately, as well as in combination, to predict material properties. The reason for combining several measured parameters for material characterization is the increased robustness against disturbing influences such as material variations and surface treatment.

In previous work, a similar attempt was made: power scale laws (PSLs), magnetic Barkhausen noise (MBN), and MAT results were compared with each other on the same series of neutron-irradiated nuclear reactor pressure vessel steel material [24]. However, DBTT values were taken from the literature; they were not directly measured in the investigated specimens.

In the present work, specimens of two different steels of eastern and western RPV design were investigated. The results obtained from measurements carried out using 3MA- 
X8 and MAT techniques on Charpy specimens were compared, before and after neutron irradiation at different neutron fluences, and were correlated with different measured mechanical properties. 3MA-X8 and MAT data, measured on the same specimen series, were collected into a common database and normalized so that they could be quantitatively compared with each other to study their reliability and sensitivity. Finally, a regression analysis was performed to predict neutron-irradiation-induced damage, and conclusions were drawn about the potential applicability of the method for nondestructive evaluation of RPV steel degradation. These results provide information complementary to that obtained from destructive tests of surveillance specimens, which are currently assumed to represent the whole component and cannot account for possible local material variations.

\section{Materials and Methods}

\subsection{Materials and Mechanical Tests}

To characterize the damage caused by neutron irradiation, two types of RPV materials were considered: western RPV material A508 Cl.2 and eastern RPV material 15Kh2NMFA. A large part of the Lemoniz reactor vessel, a Spanish reactor of the western type that was never in operation, was chosen to manufacture Charpy specimens at the Belgian Nuclear Research Centre (SCK CEN) [25,26]. ISO-V Charpy specimens were cut out from $3 / 4$ depth. Figure 1 shows the geometry of the Charpy specimen and the dimensions as well as the definition of the T-L orientation. The T-L specimen orientation was selected according to ASTM E23-16b (Standard Test Methods for Notched Bar Impact Testing of Metallic Materials) except if otherwise stated.
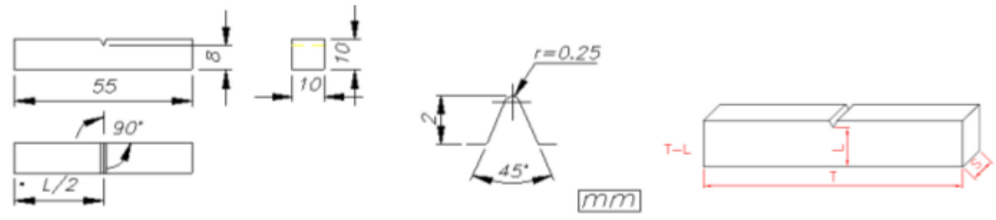

Figure 1. Schematic representation of ISO-V Charpy specimens.

The chemical composition was measured with a spark atomic emission spectrometer (Spectromaxx LMX06) (Table 1). The working method and manipulations were conducted according to the ASTM E415 standard. The typical heat treatment of RPV forgings consists of quenching, tempering, and postweld heat treatment; methods and conditions are described in ASME and ASTM specifications.

Table 1. Chemical composition (wt \%) of A508 Cl.2 base metal, as measured by optical emission spectroscopy at the Belgian Nuclear Research Centre (SCK CEN) on a Charpy specimen.

\begin{tabular}{ccccccccc}
\hline $\mathbf{C}$ & $\mathbf{M n}$ & $\mathbf{S i}$ & $\mathbf{S}$ & $\mathbf{P}$ & $\mathbf{C r}$ & $\mathbf{N i}$ & $\mathbf{M o}$ & $\mathbf{C u}$ \\
\hline 0.201 & 0.578 & 0.27 & 0.0085 & 0.0091 & 0.372 & 0.668 & 0.599 & 0.0472 \\
\hline
\end{tabular}

A part from original eastern 1000 MW RPV steel was provided. ISO-V Charpy specimens were cut out from the $\frac{1}{4}$ depth. The 15Kh2NMFA (CrNiMoV) forging steel was manufactured by the IZHORA company (Russia) for a 1000 MW WWER (Water Water Energy Reactor). The original heat number was 181,358, and the forging steel was produced according to Russian specification TU 108.765-78. The chemical composition of 15Kh2NMFA steel is provided in Table 2.

Table 2. Chemical composition (wt \%) of the 15Kh2NMFA material.

\begin{tabular}{cccccccccc}
\hline $\mathbf{C}$ & $\mathbf{M n}$ & $\mathbf{S i}$ & $\mathbf{S}$ & $\mathbf{P}$ & $\mathbf{C r}$ & $\mathbf{N i}$ & $\mathbf{M o}$ & $\mathbf{V}$ & $\mathbf{C u}$ \\
\hline 0.16 & 0.42 & 0.29 & 0.008 & 0.012 & 1.97 & 1.29 & 0.52 & 0.12 & 0.12 \\
\hline
\end{tabular}


The microstructure of the as-received specimens was a mixed-tempered ferrite-bainite structure. After manufacturing Charpy specimens from western RPV material A508 C1.2 and from eastern RPV material 15Kh2NMFA, one part of them was mechanically tested and the other parts were nondestructively investigated. After the nondestructive examination (Sections 2.2 and 3.2), this set of specimens was divided into three sets of specimens for neutron irradiation. They were neutron-irradiated in the BR2 reactor at three different irradiation fluences $(\mathrm{E}>1 \mathrm{MeV})$ in the primary water pool at an irradiation temperature of $\sim 100-120^{\circ} \mathrm{C}$ (Tables 3 and 4 ). The neutron irradiation was performed in a specially designed rig called NOMAD_3 [27], where 24 Charpy specimens were directly irradiated. This ensured that the damage created was large enough to be detected by nondestructive analysis. The fluence achieved was between 1.55 and $7.90 \times 10^{19} \mathrm{n} / \mathrm{cm}^{2}(\mathrm{E}>1 \mathrm{MeV})$. Four Charpy specimens for each irradiation level (low, middle, and high fluence) were available. Subsequently, the irradiated specimens were nondestructively investigated. To correlate the results of the micromagnetic testing measurements with the mechanical properties of the same specimens, several mechanical tests were conducted on Charpy specimens after they were nondestructively characterized. They were tested using an instrumented pendulum according to ISO 148-1 and ASTM E23 for the as-received nonirradiated and neutron-irradiated materials. Uniaxial tensile tests were performed with a crosshead rate of $0.2 \mathrm{~mm} / \mathrm{min}$, according to ASTM standards E8M and E21 on a conventional static universal tensile test machine. Vickers hardness HV10 tests were performed according to ASTM 92-17 on each Charpy specimen after neutron irradiation.

\subsection{Micromagnetic Methods}

Nondestructive methods for materials characterization are based on physical principles that are correlated to macroscopic physical properties and microscopic effects.

Micromagnetic techniques are widely used for the nondestructive characterization of the material properties of ferromagnetic steels and are based on the correlation between the magnetic properties of ferromagnetic materials and their mechanical-technological characteristics, which are dependent on the microstructure. This correlation is related to microstructure interaction with both the magnetic structure (Bloch walls) as well as the dislocations $[7,14,15]$.

The requirements for the procedure for measurement of magnetic hysteresis behavior are strict: the test specimen to be measured must be long and rod-shaped and must be magnetized as homogeneously as possible at low frequency ( $\mathrm{mHz}$ range). The magnetic flux induced in the test specimen must be measured by a coil surrounding the test specimen. For these reasons, direct measurement of the hysteresis curve is unsuitable for practical application to components. Several magnetic methods are suitable for the characterization of ferromagnetic materials (such as RPV base and weld materials). The following effects are often used in micromagnetic nondestructive testing: minor hysteresis loops, magnetic Barkhausen noise, harmonics analysis in the time domain signal of the magnetic tangential field strength, eddy currents, and incremental permeability.

Generally, micromagnetic measuring devices contain a magnetization unit, a probe, and a unit for measurement control and data processing (usually a PC). Depending on the design of the magnetization unit as well as the measurement parameters, different material depths and areas can be investigated. Micromagnetic methods can, therefore, be used to analyze a controllable fraction of the specimen volume. Commercial micromagnetic devices use different effects to describe the material's condition.

Fraunhofer IZFP developed the 3MA technique, which indirectly and nondestructively determines mechanical material properties using a one-sided access micromagnetic sensor. 3MA is based on a combination of several magnetic methods and has been described in previous studies in detail [16-18]. The latest implementation of 3MA is 3MA-X8, which was applied in this work [19]. 3MA-X8 is a variant of 3MA, defined around a minimalistic, rugged sensor design, using the magnetization coil on a U-shaped core as the only sensing element. 3MA-X8 uses low-frequency excitation ( $f<20 \mathrm{kHz}$ ) and offers 
high-speed multichannel measurement (>>100 measurements/s on 3, 8, or more channels synchronously, depending on the exact device variant). Compared with previous implementations of 3MA, 3MA-X8 does not contain Barkhausen noise analysis. Harmonics analysis, eddy current incremental permeability analysis, and eddy current impedance analysis are accomplished by supplying a voltage signal of two superimposed frequencies to the electromagnet. The drive current depends on the material contacted by the probe and is analyzed along with the voltage to extract characteristic parameters (Figures 2-4) that describe the magnetization behavior, which is then correlated to the mechanical material properties. Due to the lower frequency range compared with previous 3MA implementations, a higher penetration depth of the magnetic field is reached. Within the present application, this is an important advantage, given the correlation of the magnetic properties to the material properties, such as DBTT and yield strength, as these are also integral values of the examined specimens.

The following section describes the 3MA-X8 analysis in more detail:

I. Eddy currents (ECs) arise in a material if it is exposed to an alternating magnetic field and depend on the electrical conductivity $\sigma$ and the magnetic permeability $\mu$ of the material $[16,17]$. The higher-frequency EC-affected impedance $(Z)$ is not constant throughout the rather low-frequency hysteresis loop. Therefore, $\mathrm{Z}$ describes a loop in the impedance plane throughout one hysteresis cycle [19]. Figure 2 illustrates the parameters derived from this loop.

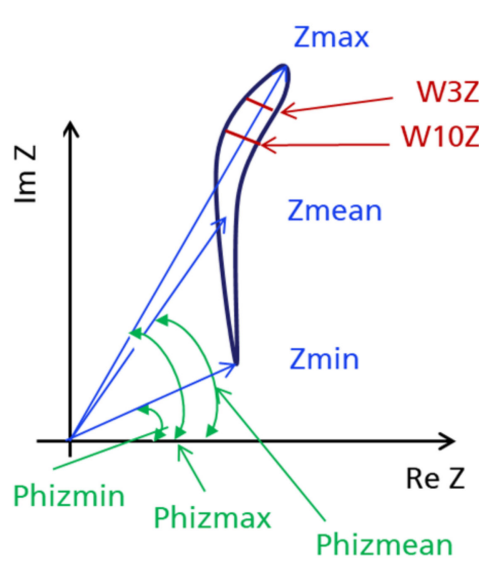

\begin{tabular}{|l|l|}
\hline Parameter & Explanation \\
\hline Zmean & $\begin{array}{l}\text { Average of absolute impedance } \\
\text { of impedance loop }\end{array}$ \\
\hline Zmin & $\begin{array}{l}\text { Minimum of absolute impedance } \\
\text { of impedance loop }\end{array}$ \\
\hline Zmax & $\begin{array}{l}\text { Maximum of absolute impedance } \\
\text { of impedance loop }\end{array}$ \\
\hline Phizmean & Phase of the average impedance \\
\hline Phizmin & Phase of the minimum impedance \\
\hline Phizmax & Phase of the maximum impedance \\
\hline W3Z & $\begin{array}{l}\text { Width of the impedance loop } \\
\text { at } 3 \% \text { of maximum }\end{array}$ \\
\hline W10Z & $\begin{array}{l}\text { Width of the impedance loop } \\
\text { at } 10 \% \text { of maximum }\end{array}$ \\
\hline
\end{tabular}

Figure 2. Schematic illustration of the impedance loop and derived parameters.

II. Incremental permeability (IP) analysis is a method of separating magnetic permeability information from electrical conductivity information in EC analysis [16,17]. Plotting the change in EC coil impedance (DZ) against drive voltage U lecads to an incremental permeability plot (Figure 3, left) [19]. Several parameters are derived from the incremental permeability curve (Figure 3 ).

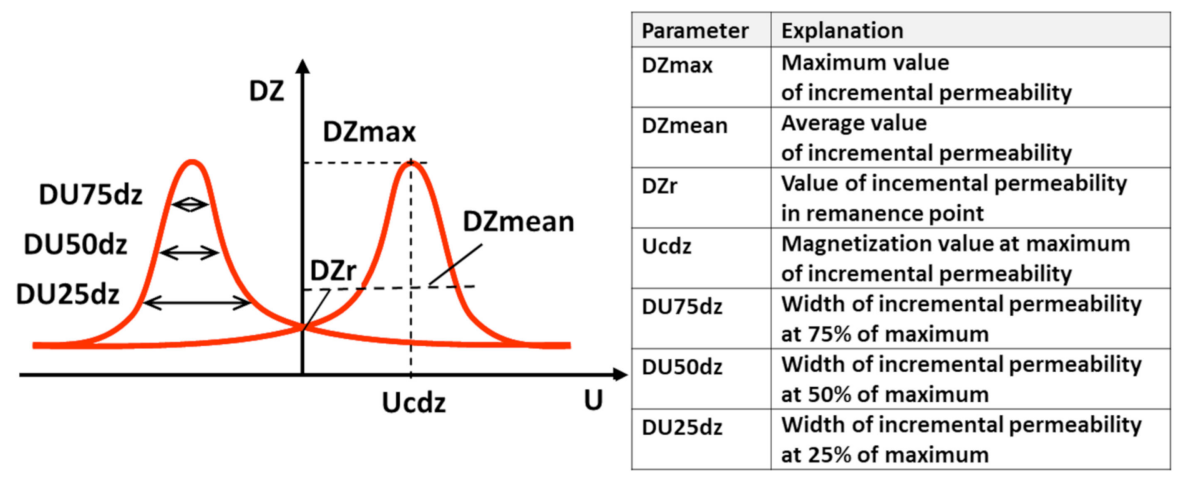

Figure 3. Schematic illustration of the incremental permeability curve and the parameters derived. 
III. The measured magnetizing current exhibits a low-frequency distortion due to hysteresis in the magnetic circuit. The fundamental and harmonic components can be determined numerically using a fast Fourier transform; thus, the distortions of the magnetizing current are quantified. The harmonic components determined through this procedure allow for the determination of material properties (Figure 4) [19].

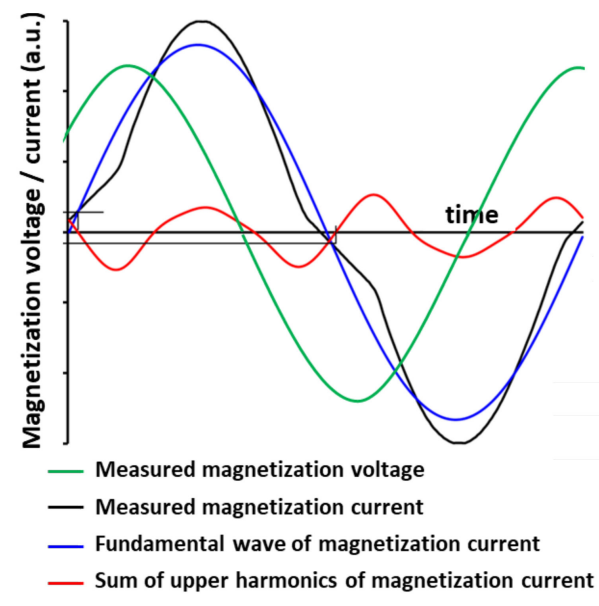

\begin{tabular}{|c|c|}
\hline Parameter & Explanation \\
\hline Vmag & Amplitude of magnetization voltage \\
\hline Imag & Amplitude of magnetization current \\
\hline K & $\begin{array}{l}\text { Distortion factor of magnetization current } \\
\text { (see below) }\end{array}$ \\
\hline A3 & Amplitude of third harmonic \\
\hline P3 & $\begin{array}{l}\text { Phase shift of third harmonics } \\
\text { to fundamental wave }\end{array}$ \\
\hline \multicolumn{2}{|c|}{$K=100 \% \cdot \sqrt{\frac{A_{3}{ }^{2}+A_{5}{ }^{2}+A_{7}{ }^{2}}{A_{1}{ }^{2}}}$} \\
\hline A5, A7: & $\begin{array}{l}\text { Amplitudes of } 5 \text { th and } 7 \text { th harmonics } \\
\text { only used for internal calculation of distortion factor) } \\
\text { Amplitude of fundamental }\end{array}$ \\
\hline
\end{tabular}

Figure 4. Schematic illustration of the harmonic analysis in the time domain signal of the magnetization current.

Figure 5 shows the 3MA-X8 device, including a probe and a PC. The 3MA-X8 measurements were performed at a magnetization frequency of $50 \mathrm{~Hz}$, a magnetization current voltage of $2 \mathrm{~V}$, and a superimposed EC frequency of $2000 \mathrm{~Hz}$. The 3MA-X8 device is controlled by modular measuring system (MMS) software. The output of the data acquisition and evaluation module was a set of 21 magnetic parameters derived from the 3MA-X8 measurements, as listed on the right-hand side of Figures 2-4. A specimen holder and a probe holder improved reproducibility by minimizing positioning variations.
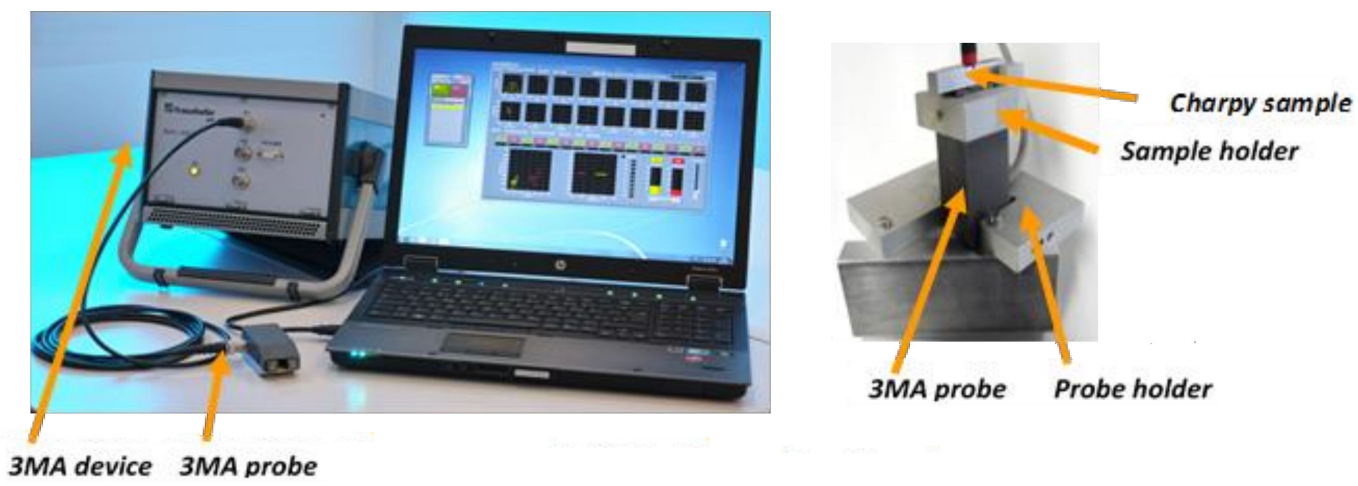

Figure 5. The micromagnetic multiparameter microstructure and stress analysis (3MA)-X8 system, including 3MA-X8 device, probe, and PC (left); (right) specimen holder and probe holder.

The Centre for Energy Research developed and applied the MAT method. The MAT method uses the systematic measurement of large families of minor hysteresis loops from minimum amplitudes up to, possibly, the maximum (major) on degraded ferromagnetic samples/objects. From the large volume of recorded data, the data that reflect material degradation in the most sensitive, or otherwise most convenient, manner are applied for evaluation of the degradation. These data, best-adapted for the investigated case, were used as the MAT parameter(s), and their dependence on an independent variable accompanying the inspected degradation is referred to as the MAT degradation function(s). 
The magnetic induction method appears to be the easiest method of systematic measurement for MAT. A specially designed permeameter [28], with a magnetizing yoke, was applied for the measurement of families of minor loops of a magnetic circuit's differential permeability. Measurement of the hysteresis loops was performed by a magnetizing yoke, which is placed on the flat surface of the Charpy specimens. A C-shaped laminated Fe-Si transformer core was used. The yoke had a cross-section of $10 \times 5 \mathrm{~mm}$ and a total external length of $18 \mathrm{~mm}$. This size was chosen to fit the size of the investigated specimens. The specimen holder, designed for hot-cell measurements, is shown in Figure 6 [29]. The driving coil wound on the yoke produces triangular variations in the applied magnetic field, with stepwise increasing amplitudes and a fixed slope magnitude in all the triangles (Figure 7a).

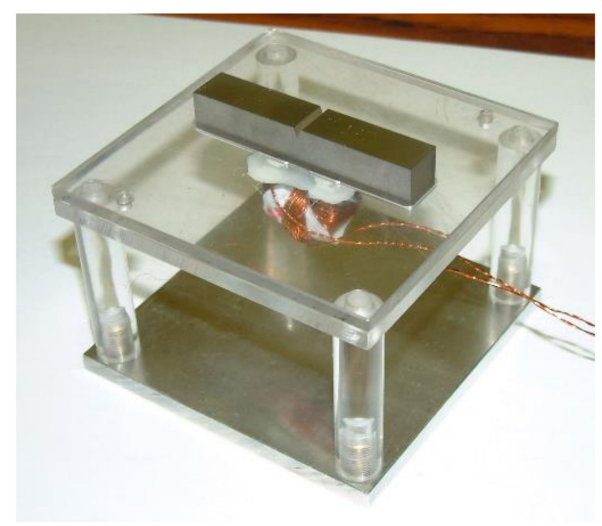

Figure 6. Photo of the specimen holder. A Charpy specimen is placed on the top (V-notch is opposite the magnetizing yoke) [29].
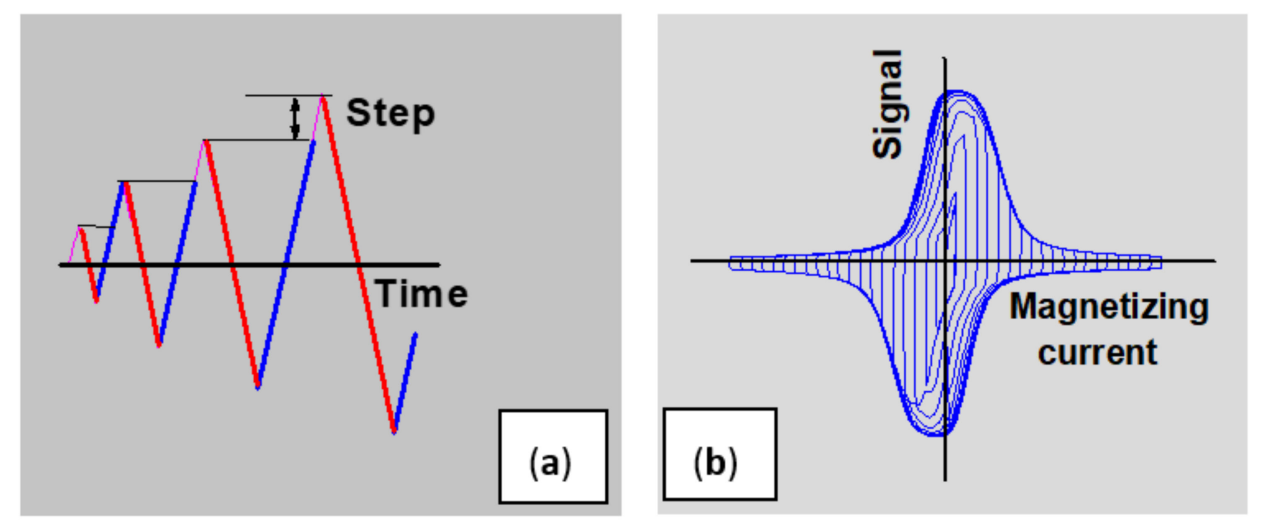

Figure 7. The time variation of the magnetizing current (a) and the measured permeability loops (b) [30].

The signal coil picks up the induced voltage, proportional to the differential permeability of the sample. This triangular variation of the magnetizing field, with time $t$ and a voltage signal $U$, is induced in the pick-up coil for each $k$ th sample:

$$
U\left(\mathrm{~d} F / \mathrm{d} t, F, A_{j}, \varepsilon_{k}\right)=K \times \partial B\left(\mathrm{~d} F / \mathrm{d} t, F, A_{j}, \varepsilon_{k}\right) / \partial t=K \times \mu\left(\mathrm{d} F / \mathrm{d} t, F, A_{j}, \varepsilon_{k}\right) \times \mathrm{d} F / \mathrm{d} t,
$$

where $K$ is a constant determined by the geometry of the sample and by the experimental arrangement; $\varepsilon$ is the independent degradation variable, in our case, Vickers hardness, yield strength, or transition temperature. As long as $F=F(t)$ sweeps linearly with time, i.e., $|\mathrm{d} F / \mathrm{d} t|$ is (the same) constant for measurement at each of the samples, Equation (1) states that the measured signal is simply proportional to the differential permeability $\mu$ of the measured magnetic circuit as it varies with the applied field $F$ within each minor loop amplitude $A_{j}$ for each $k$ th measured sample. If we wish to obtain correct results that are not 
influenced by any previous remanence, each sample has to be thoroughly demagnetized before it is measured.

The permeameter works under the control of a notebook, which sends the steering information to the function generator and collects the measured data. An input/output data acquisition card accomplishes the measurement. The computer registers two data files for each measured family of minor loops. The first one contains detailed information about all the preselected parameters of the demagnetization and the measurement. The other file holds the course of the voltage signal $U$ induced in the pick-up coil as a function of time $t$ and of the magnetizing current $I_{F}$ and/or field $F$. As an illustration, Figure $7 \mathrm{~b}$ presents the families of permeability loops. Large amounts of data were generated, and our task was to compare them and find the most suitable data for characterizing the changes between samples.

Instead of keeping the signal and the magnetizing field in shapes of continuous timedependent functions, it is practical to interpolate the family of data for each $\varepsilon_{k}$ sample into a discrete square $(i, j)$ matrix, $U\left(F_{i}, A_{j}, \varepsilon_{k}\right)$, with a suitably chosen step, $\Delta \mathrm{A}=\Delta F$. Because $\mathrm{d} F / \mathrm{d} t$ is a constant, identical for all measurements within one experiment, it is not necessary to write it explicitly as a variable of $U$. MAT is a relative method (practically all the nondestructive methods are relative), and the most suitable information regarding the degradation of the investigated material can be contained in the variation of any element of such matrices as a function of $\varepsilon$, relative to the corresponding element of the reference matrix $U\left(F_{i}, A_{j}, \varepsilon_{0}\right)$. So, we divided all $U\left(F_{i}, A_{j}, \varepsilon_{k}\right)$ elements by the corresponding elements $U\left(F_{i}, A_{j}, \varepsilon_{0}\right)$ of the reference sample matrix and obtained the normalized elements of the matrices of relative differential permeability $\mu\left(F_{i}, A_{j}, \varepsilon_{k}\right)=U\left(F_{i}, A_{j}, \varepsilon_{k}\right) / U\left(F_{i}, A_{j}, \varepsilon_{0}\right)$, and their proper sequences

$$
\mu\left(F_{i}, A_{j}, \varepsilon\right)=U\left(F_{i}, A_{j}, \varepsilon\right) / U\left(F_{i}, A_{j}, \varepsilon_{0}\right)
$$

as normalized $\mu$-degradation functions of the inspected material. These $\mu$ elements are referred to as MAT descriptors, and they characterize the degradation of the material.

Numerous MAT descriptors are calculated during evaluation; their number depends on the density and how $\mu\left(F_{i}, A_{j}, \varepsilon_{k}\right)$ points are calculated. Normally, about 1000 MAT descriptors are calculated. The majority of them do not reflect the correlation between magnetic parameters and actual material degradation. The purpose of our evaluation is to choose the elements that provide the best correlation between MAT parameters and the independent parameter from this big data pool. These parameters are called optimally chosen MAT descriptors, and they are provided below in the Results section. The choice is correct if these parameters have the best sensitivity and yield good reproducibility simultaneously. The MAT evaluation process is described in detail in [23].

3MA-X8 and MAT measurements were carried out similarly: to adequately perform measurements in the hot cell, the specimens were placed on the top of the 3MA-X8 and MAT probes, respectively, to allow the easy replacement of specimens by a manipulator. The 3MA-X8 and MAT devices were placed outside the hot cell for remote control of the measurement.

Both 3MA-X8 and MAT are comparative-type measurement methods. This means that the measured magnetic parameters describe the material behavior from the magnetic point of view. For the quantitative characterization of specimens with unknown mechanical properties, an initial calibration/training process is needed on a well-defined calibration set of specimens (with known target properties, e.g., DBTT or hardness). A polynomial function describing the relation between all collected micromagnetic parameters, the magnetic fingerprint (MFP), and the target quantity (e.g., hardness, DBTT) of each material can be determined via regression analysis based on a database of calibration specimen measurements. Assuming a regression analysis is used, a simple calibration using a polynomial function can be written as $Y=a_{0}+a_{1 \times 1}+a_{2} X_{2}+\ldots+a_{N} X_{N}$, where $Y$ is the target quantity (e.g., DBTT or hardness), $a_{i}$ are the coefficients, $X_{i}$ are the measured parameters (components of the MFP), and N is the number of selected measured parameters [18]. The parameters are selected based on the least-squares algorithm. This polynomial function is 
generated empirically since there is no physical equation that describes the dependency between individual magnetic parameters and mechanical properties. The detailed calibration procedure is described in [18]. The trained system can be used to determine target quantities of specimens of the same material after a prior recording of the micromagnetic parameters.

\section{Results}

\subsection{Mechanical Properties}

The BR2 material test reactor at SCK CEN, with a nominal power of $125 \mathrm{MW}$ and unique, adaptable core configuration, is the most powerful material test reactor currently operating in Europe. The neutron spectrum is typical of a research reactor, with thermal fluxes between $7 \times 10^{13}$ and to $10^{15} \mathrm{n} /\left(\mathrm{cm}^{2} \mathrm{~s}\right)$ and fast fluxes $(\mathrm{E}>0.1 \mathrm{MeV})$ between $1 \times 10^{13}$ and $6 \times 10^{14} \mathrm{n} /\left(\mathrm{cm}^{2} \mathrm{~s}\right)$. Like all nuclear reactors, there is no single neutron energy. The actual fast fluence values for all Charpy specimens were measured (Tables 3 and 4) by Fe dosimeters. The ${ }^{235} \mathrm{U}$ equivalent fission neutron flux was calculated from the ${ }^{54} \mathrm{Mn}$ activity formed by the ${ }^{54} \mathrm{Fe}(\mathrm{n}, \mathrm{p}){ }^{54} \mathrm{Mn}$ reaction. The flux (fluence) was calculated using the ${ }^{235} \mathrm{U}$ fission spectrum averaged cross-section $\langle\sigma\rangle=81.7 \mathrm{mb}$, adopted from [31]. The equivalent fission fluence was converted to a fast fluence $(\mathrm{E}>1 \mathrm{MeV})$ in Fe to provide the material damage of the reactor pressure vessel specimens.

First, the actual fluence values for all Charpy specimens were measured (Tables 3 and 4 ). The results of the Charpy impact tests are shown in Figure 8 for A508 Cl.2 and 15Kh2NMFA. An irradiation-induced embrittlement shift, ranging between 100 and $200{ }^{\circ} \mathrm{C}$, was achieved.

A correlation usually exists between the yield strength increase, hardening, and embrittlement. To obtain some estimations on the correlation between yield strength increase and the embrittlement $\left(\Delta \mathrm{T}_{41 \mathrm{~J}}\right)$, some additional tests were performed. The first was Vickers hardness at HV5 (Figure 9). Correlations between hardness increase and neutron fluence were found for both steels. In Figure 10, the increase in yield strength $\Delta \sigma_{Y}$ is plotted for the two grades at the three neutron fluence levels. The increase in yield strength was similar for both grades at the tested fluence levels, even though the initial yield strength was different between the two grades. All test results are summarized in Tables 3 and 4 for A508 Cl.2 and 15kHNMFA steel, respectively.

Table 3. Fast fluence ( $\mathrm{E}>1 \mathrm{MeV}$ ), Vickers hardness (HV5), yield strength (hardening $\Delta \sigma_{\mathrm{y}}$ ), and ductile to brittle transition temperature (DBTT; embrittlement $\Delta \mathrm{T}_{41 \mathrm{~J}}$ ) for A508 Cl.2. RT, room temperature.

\begin{tabular}{ccccc}
\hline A508 C1.2. & $\begin{array}{c}\text { Fast Fluence }(\mathbf{E}>\mathbf{1 ~ M e V )} \\
\left(\times \mathbf{1 0}^{\mathbf{1 9}} \mathbf{n} / \mathbf{c m}^{\mathbf{2}}\right)\end{array}$ & $\begin{array}{c}\text { Vickers Hardness } \\
\mathbf{H V 5}(\boldsymbol{\Delta} \mathbf{H V})\end{array}$ & $\begin{array}{c}\text { Yield Strength } \\
\text { @RT }(\mathbf{M P a})\left(\boldsymbol{\Delta} \boldsymbol{\sigma}_{\mathbf{y}}\right)\end{array}$ & $\begin{array}{c}\mathbf{D B T T} \\
\mathbf{T}_{\mathbf{4 1 j}}\left({ }^{\circ} \mathbf{C}\right)(\boldsymbol{\Delta} \mathbf{T} \\
\mathbf{4 1 j})\end{array}$ \\
\hline Baseline & 0 & $181.2 \pm 2.8$ & 448 & $-33 \pm 9$ \\
\hline Low fluence & 1.55 & $237.9 \pm 2.8(56.7)$ & $710(262)$ & $76 \pm 15(109)$ \\
\hline Medium fluence & 4.38 & $254.4 \pm 1.5(73.2)$ & $793(345)$ & $125 \pm 15(158)$ \\
\hline High fluence & 7.04 & $258.5 \pm 3.1(77.3)$ & $823(375)$ & $126 \pm 15(159)$ \\
\hline
\end{tabular}

Table 4. Fast fluence (E $>1 \mathrm{MeV}$ ), Vickers hardness (HV5), yield strength (hardening $\Delta \sigma_{\mathrm{y}}$ ), and DBTT (embrittlement $\Delta \mathrm{T}_{41 \mathrm{~J}}$ ) for 15Kh2NMFA.

\begin{tabular}{|c|c|c|c|c|}
\hline 15Kh2NMFA & $\begin{array}{l}\text { Fast Fluence }(\mathrm{E}>1 \mathrm{MeV}) \\
\left(\times 10^{19} \mathrm{n} / \mathrm{cm}^{2}\right)\end{array}$ & $\begin{array}{c}\text { Vickers Hardness } \\
\text { HV5 ( } \Delta \mathrm{HV})\end{array}$ & $\begin{array}{c}\text { Yield Strength } \\
@ \text { RT }(\mathrm{MPa})\left(\Delta \sigma_{\mathrm{y}}\right)\end{array}$ & $\begin{array}{c}\mathrm{DBTT} \\
\mathrm{T}_{41 \mathrm{~J}}\left({ }^{\circ} \mathrm{C}\right)\left(\Delta \mathrm{T}_{41 \mathrm{~J}}\right)\end{array}$ \\
\hline Baseline & 0 & $226.1 \pm 5.5$ & 600 & $-51 \pm 12$ \\
\hline Low fluence & 2.78 & $278.5 \pm 3.4(52.4)$ & $875(275)$ & $88 \pm 15(139)$ \\
\hline Medium fluence & 6.83 & $292.8 \pm 3.1(66.7)$ & $973(373)$ & $136 \pm 15(187)$ \\
\hline High fluence & 7.9 & $294.1 \pm 4.5(68.0)$ & $987(387)$ & $124 \pm 15(175)$ \\
\hline
\end{tabular}




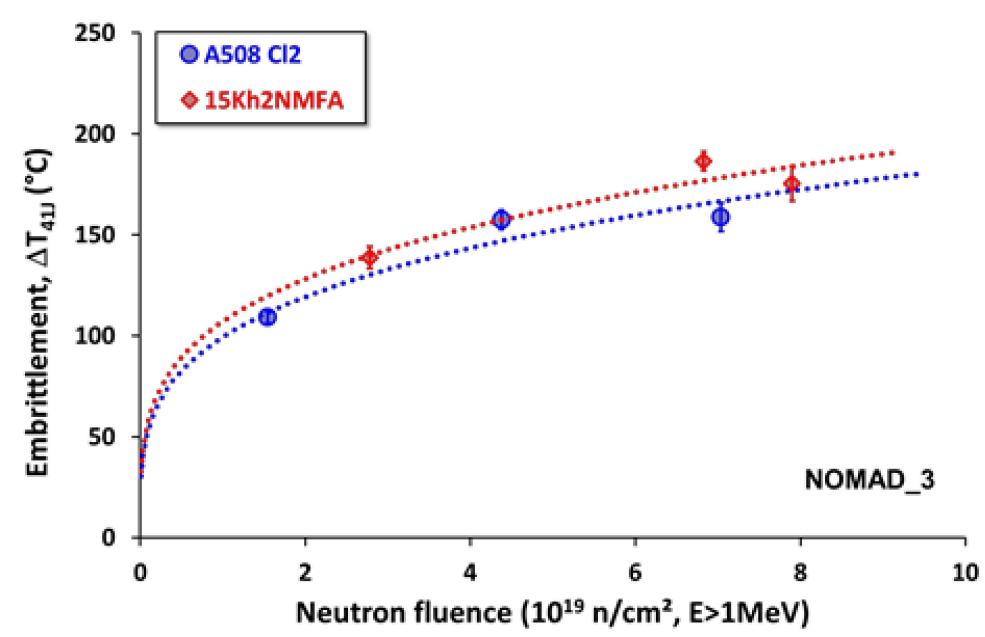

Figure 8. Embrittlement of 15Kh2NMFA and A508 Cl.2 after NOMAD_3 irradiation as a function of neutron fluence. The dashed lines are added to guide the eye (power law fit).

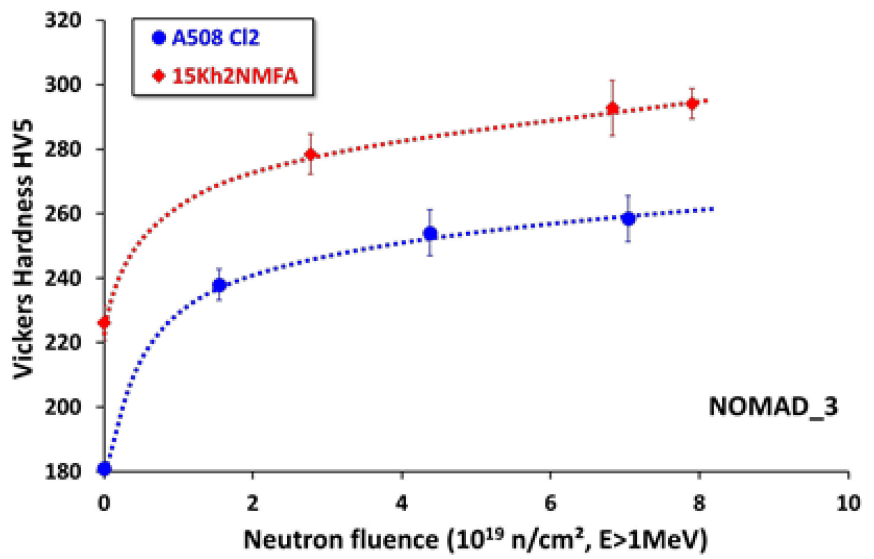

Figure 9. Vickers hardness (5kgf) for A508 Cl.2 and 15Kh2NMFA. The dashed lines are added to guide the eye.

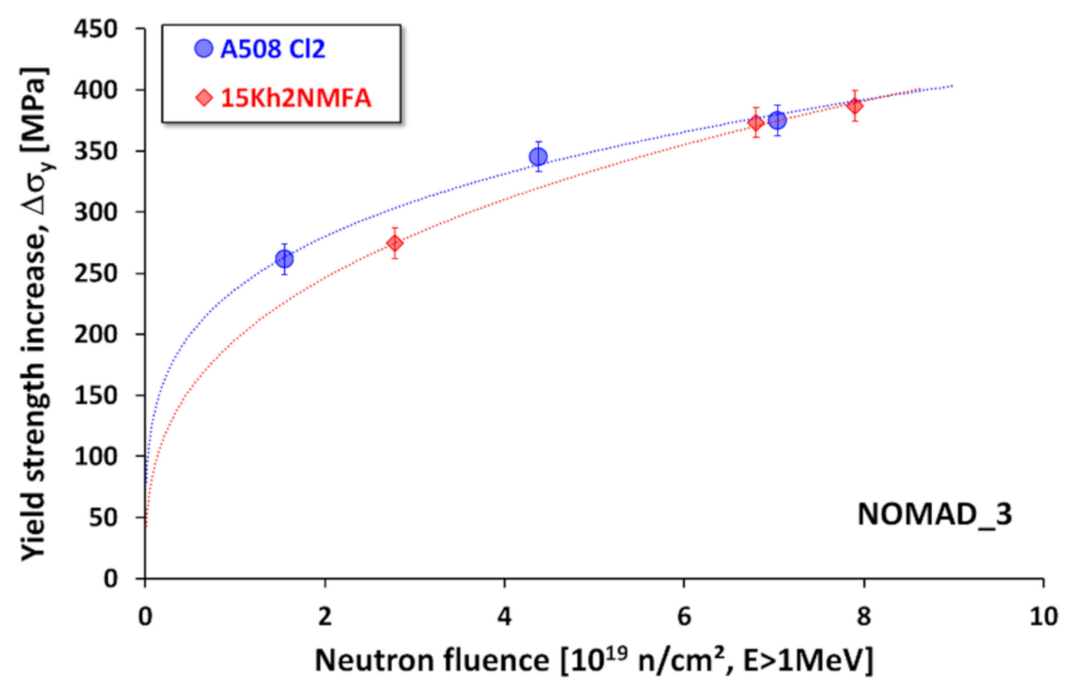

Figure 10. Tensile strength increase (hardening), tested at room temperature for A508 Cl.2 and $15 \mathrm{Kh} 2 \mathrm{NMFA}$ steels, as a function of the fast neutron fluence. The dashed lines are added to guide the eye (power law fit). 
All mechanical properties, such as hardness, yield strength, and DBTT, increased with increasing irradiation fluence. The increase in yield strength and DBTT caused by neutron irradiation for both materials was almost the same; the increase in the hardness of the eastern RPV material was slightly higher than that of the western RPV material. Additionally, we observed that hardness, yield strength, and DBTT slowly increased at middle and high fluence for the western RPV material. The same behavior was observed in terms of hardness and yield strength for the eastern RPV material. For this material, the DBTT at high fluence was slightly lower than at medium fluence. However, no conclusions can be drawn here due to the uncertainties in these values.

\subsection{Micromagnetics Results}

Both nondestructive techniques, 3MA-X8 and MAT, were applied to the specimens described in Section 2.1 using predefined measuring parameters (magnetic field amplitude and magnetization frequency) on the opposite side of the Charpy notch to avoid possible side effects that can alter the outcome of the measurements. All measurements were carried out at the Laboratory of Medium and High Activity (LMHA) at SCK CEN due to the high activation of the specimens. The exact same specimens were tested before and after neutron irradiation under the same environmental conditions: in a hot cell. Therefore, the disturbing influences of material inhomogeneity and scatter between different specimens of the same material were eliminated.

Both micromagnetic measurements recorded from Charpy specimens of RPV materials A508 Cl.2 (Figure 11) and 15Kh2NMFA (Figure 12) before and after neutron irradiation showed clear differences between the four irradiation conditions (nonirradiated; low, medium, and high fluence). We observed that the magnetic material properties of different specimens measured before irradiation were not exactly identical. After neutron irradiation, these differences were observed in the magnetic properties of specimens irradiated at the same fluence as well. Nevertheless, a trend was clearly identified: neutron irradiation caused easily measurable differences in magnetic parameters, although different procedures, 3MA-X8 or MAT, were used for measurements.

In the case of MAT measurements, the parameters are normalized by the corresponding parameter of the reference (nonirradiated) specimens. As shown in Figures 11 and 12, a clear increase in magnetic parameters was found due to neutron irradiation. This parameter depends on the material's condition. For A508 Cl.2 material, this descriptor was characterized by $F_{i}=780 \mathrm{~mA}$ and $A_{j}=1200 \mathrm{~mA}$ values, while $15 \mathrm{Kh} 2 \mathrm{NMFA}$ material was characterized by $F_{i}=30 \mathrm{~mA}$ and $A_{j}=1080 \mathrm{~mA}$.
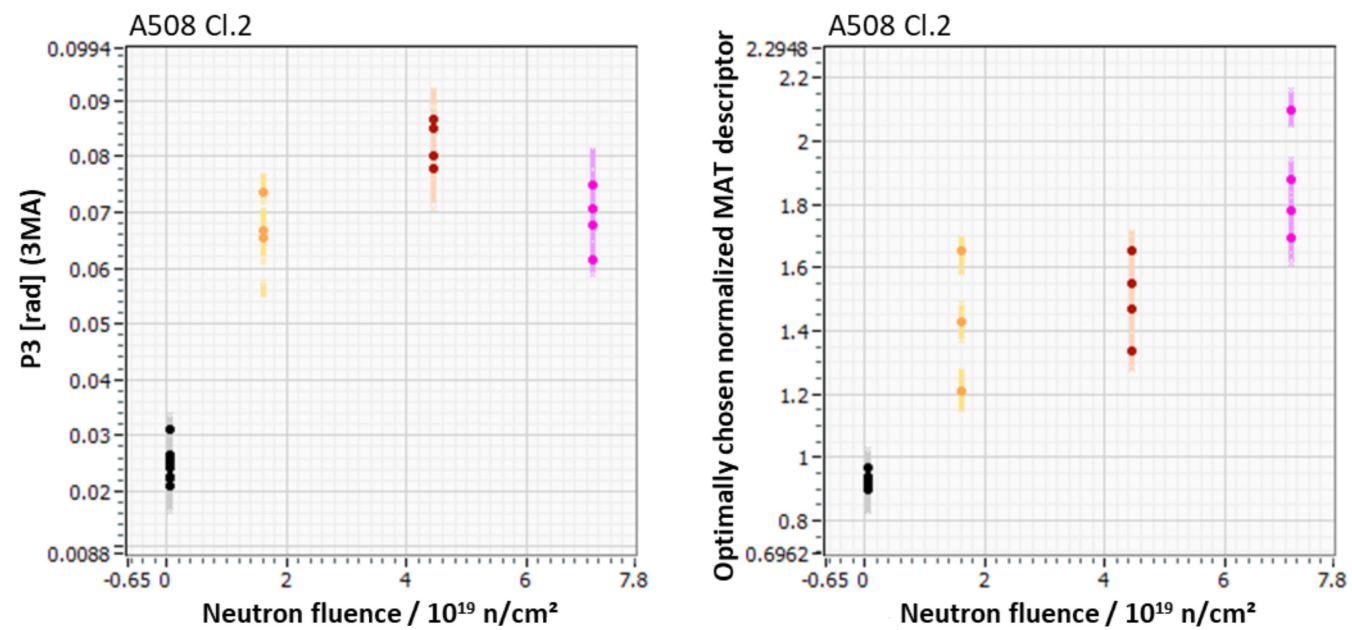

Figure 11. Dependency of the amplitude of third harmonics P3 (left) and of the magnetic adaptive testing (MAT) descriptor (right) on the fluence level for western reactor pressure vessel (RPV) material A508 Cl.2. 

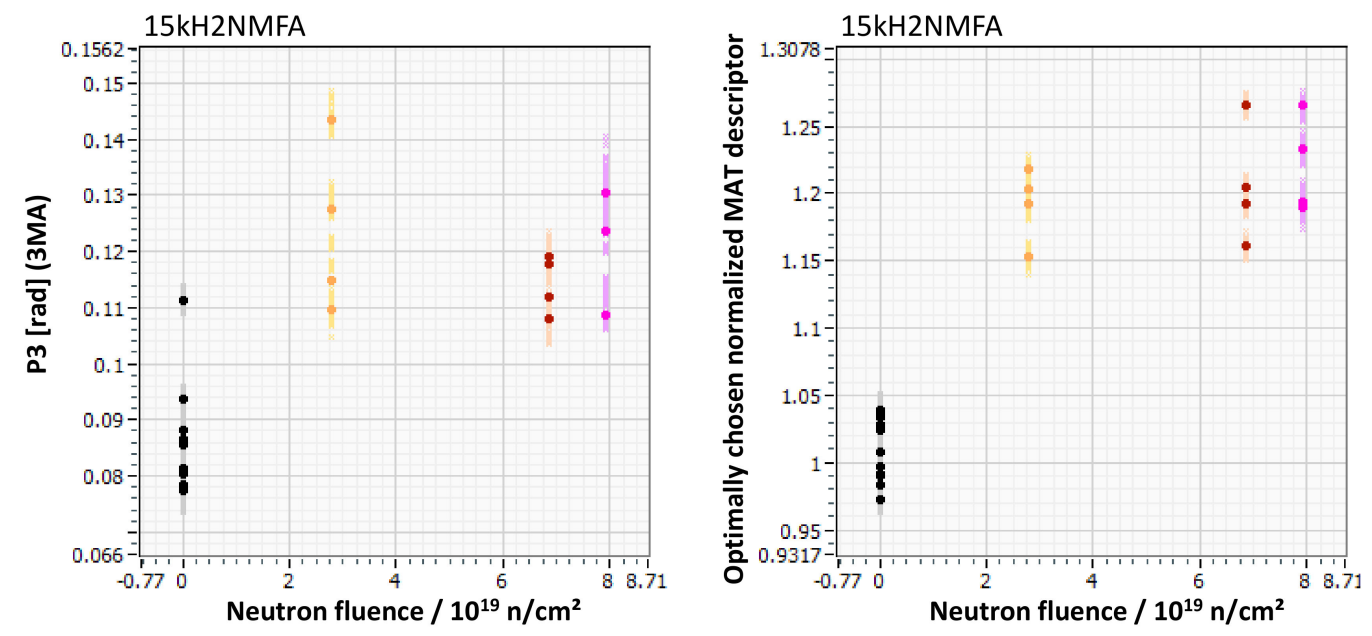

Figure 12. Dependency of the amplitude of third harmonics P3 (left) and of the MAT descriptor (right) on the fluence level for eastern RPV material 15Kh2NMFA.

In the case of 3MA-X8 measurements, several magnetic parameters (e.g., P3, A3, K, Ucdz) showed a clear trend with increasing neutron fluence. Figures 11 and 12 show the amplitude of the third harmonics P3-derived from upper harmonics analysis in the time domain signal of the magnetization current as a function of neutron fluence.

The results of the micromagnetic measurements were evaluated in terms of DBTT determined by Charpy tests, hardness, and yield strength. Trends in several quantities extracted from upper harmonics analysis and magnetic adaptive testing were observed in relation to different mechanical properties (DBTT, mechanical hardness, and yield strength).

Differences between the irradiation conditions can hardly be identified, especially between specimens irradiated at medium and high fluence. In this context, it has to be emphasized that for both materials, the mechanical properties of the specimens under the middle- and high-irradiation conditions were almost the same as well. In Figures 13-16, the same parameters as in Figures 11 and 12 are presented in terms of embrittlement (DBTT) and hardening (hardness and yield strength) for both materials and both testing methods.

We observed that the $3 \mathrm{MA}-\mathrm{X} 8$ method is more sensitive to changes in the material properties of western RPV steel A508 Cl.2, whereas the MAT method is more sensitive to the changes in the material properties of eastern RPV steel 15Kh2NMFA.
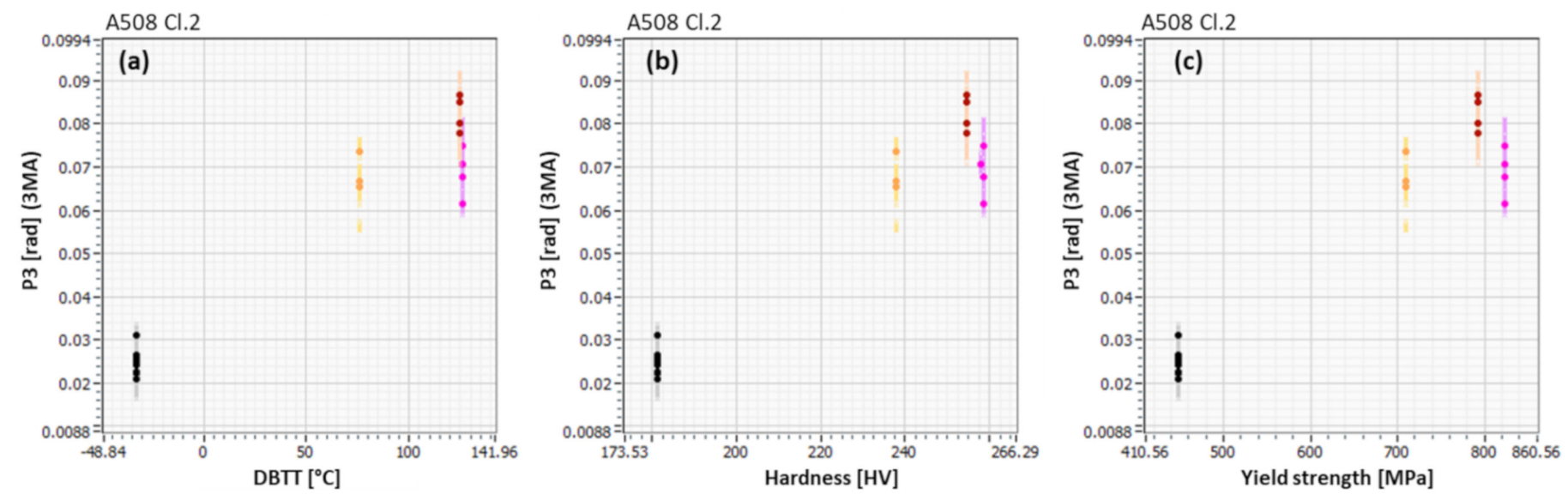

Figure 13. Dependency of the amplitude of third harmonics P3 on the ductile to brittle transition temperature (DBTT)(a), hardness (b), and yield strength (c) of western RPV material A508 Cl.2. 

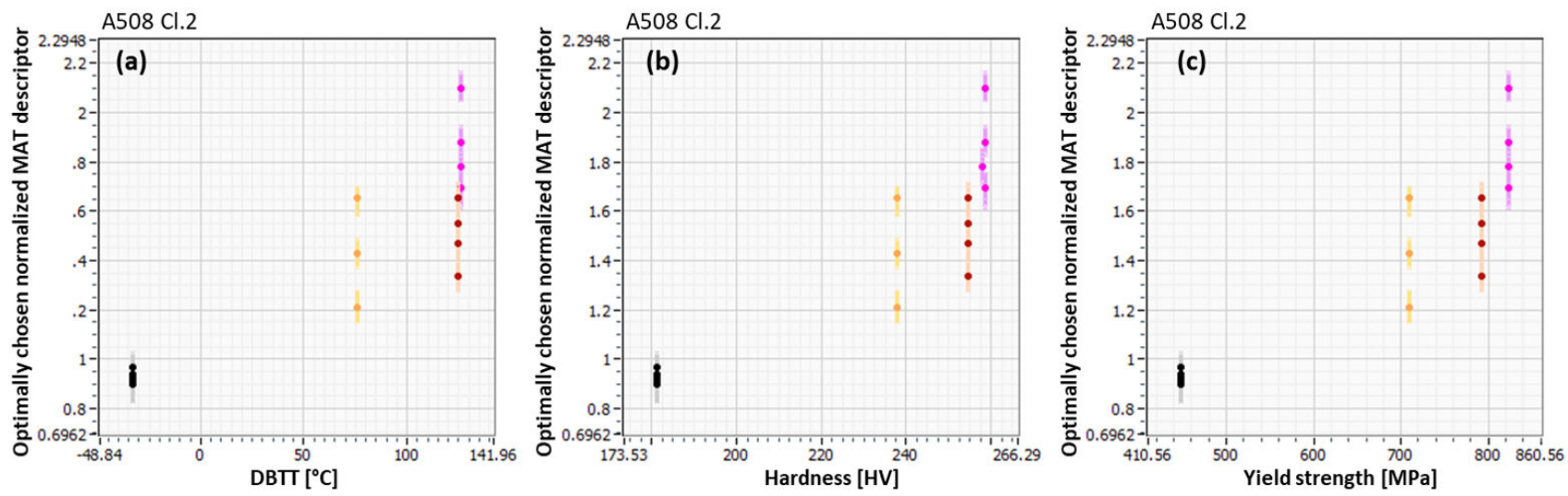

Figure 14. Dependency of the MAT descriptor on the DBTT (a), hardness (b), and yield strength (c) of western RPV material A508 Cl.2.
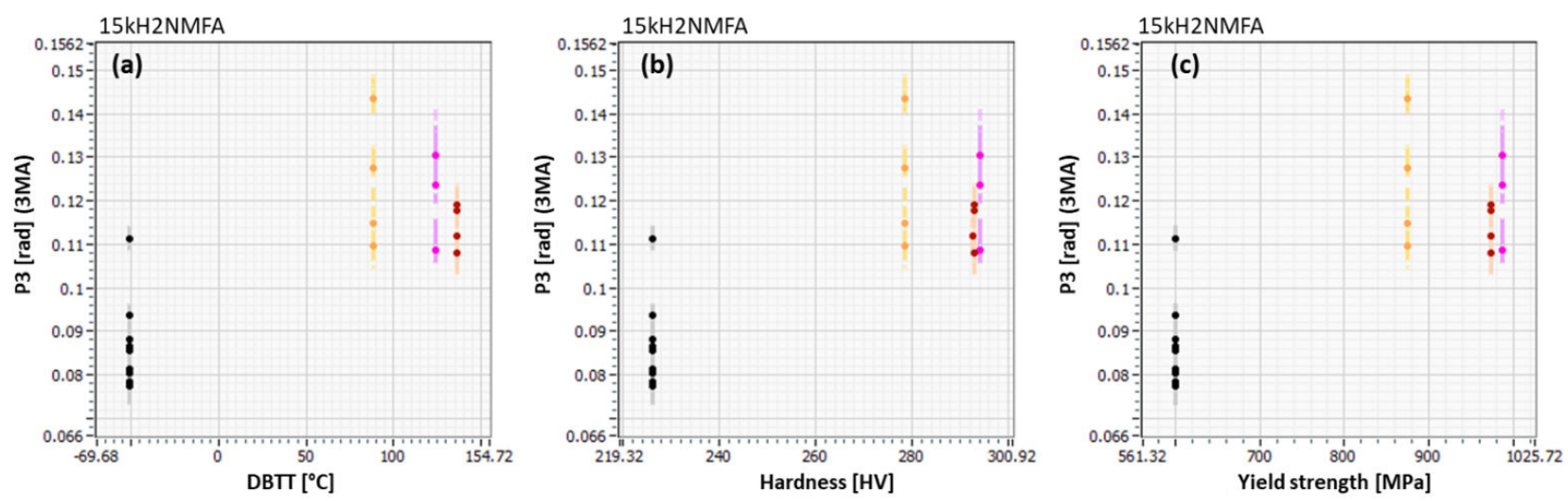

Figure 15. Dependency of the amplitude of third harmonics P3 on DBTT (a), hardness (b), and yield strength (c) of eastern RPV material 15Kh2NMFA.
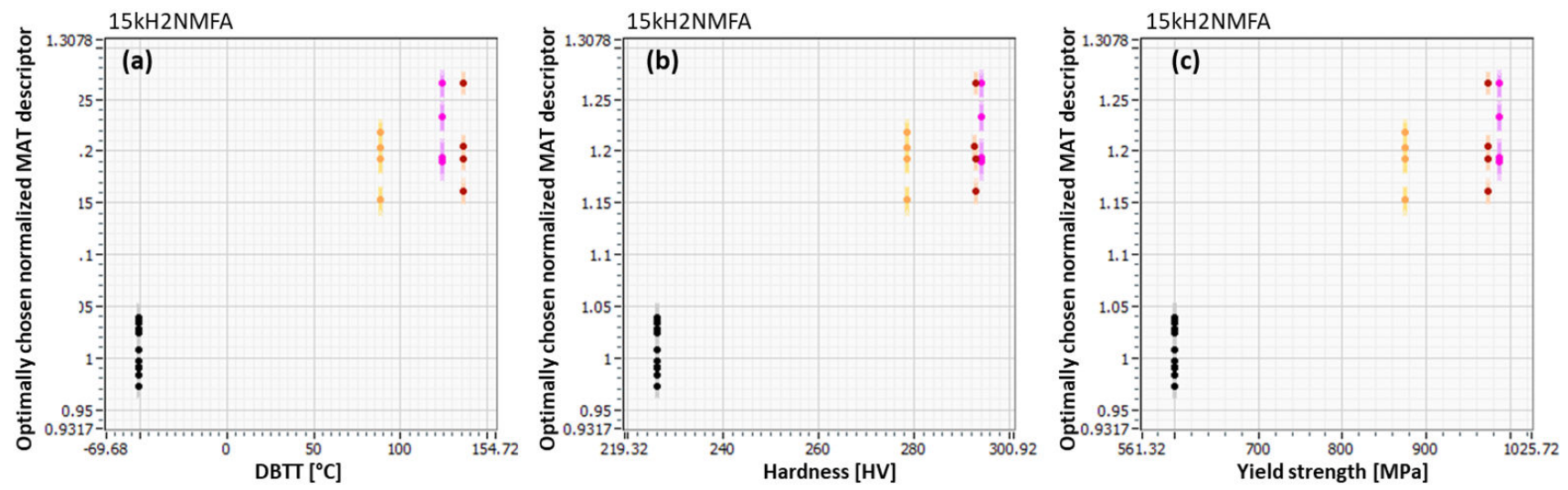

Figure 16. Dependency of the MAT descriptor on the DBTT (a), hardness (b), and yield strength (c) of eastern RPV material 15Kh2NMFA.

\subsection{Nondestructive Prediction of Embrittlement and Hardening}

All measured micromagnetic parameters were collected and classified in terms of irradiation condition, embrittlement, and hardening. The reason for using more than one measuring parameter for material characterization is the increased robustness against disturbing influences such as material variations and surface conditions (similar to the benefits of having and combining different human senses). Having collected all measured 
parameters obtained from 3MA-X8 and MAT measurements, parameters were separated into two data sets: one set for the calibration/training procedure and another set for testing. In the data set for calibration/training, all parameters obtained by means of MAT and 3MA-X8 methods on the predefined calibration set of specimens were merged with the corresponding mechanical properties. In the next step, the calibration/training procedure was conducted: polynomial functions empirically describing the relation between measured micromagnetic parameters and the target quantities (DBTT, mechanical hardness, and yield strength) were determined via regression analysis [18]. These polynomial functions quantitatively and empirically describe the correlation between mechanical properties and measured micromagnetic parameters. Finally, these polynomial functions, determined on the training set of specimens, were tested using the micromagnetic data obtained on the testing set of specimens; thus, the target quantities were estimated. Figures 17 and 18 show the results of the training (dark dots) and testing (light crosses) procedures for A508 $\mathrm{Cl} .2$ and 15Kh2NMFA, respectively. The combination of both 3MA-X8 and MAT methods allows for the prediction of mechanical properties, independent of the difference between individual specimens under the same irradiation condition.
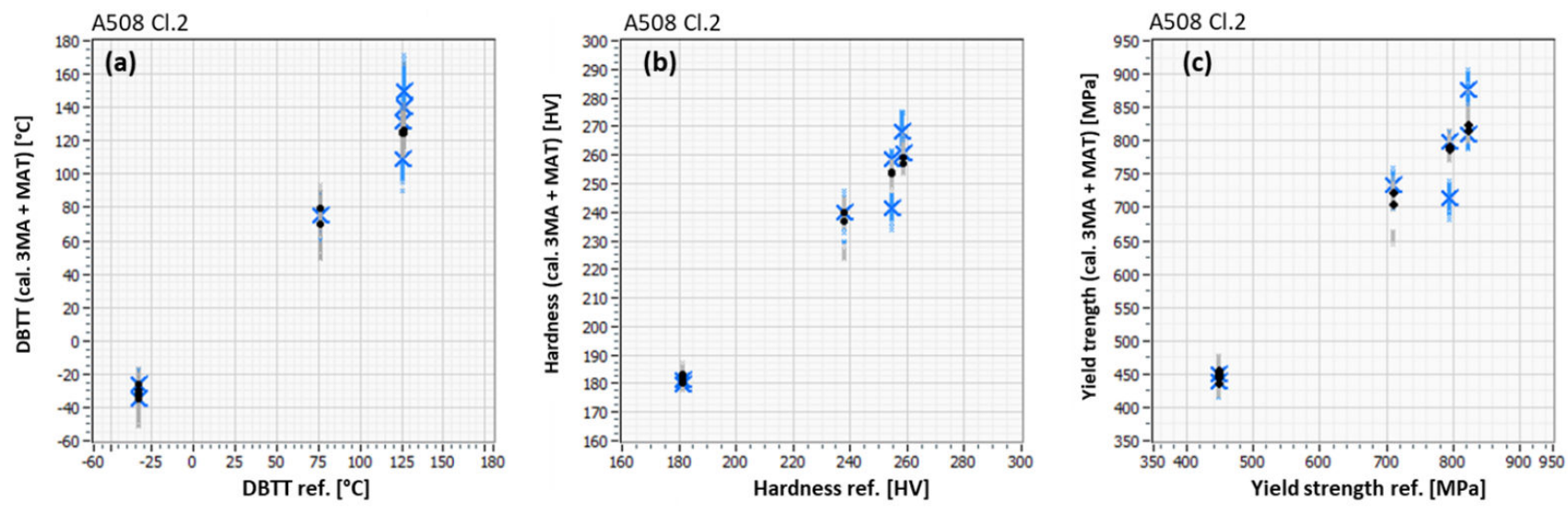

Figure 17. Prediction of DBTT (a), mechanical hardness (b), and yield strength (c) for A508 Cl.2 material using combined data from 3MA-X8 and MAT methods.
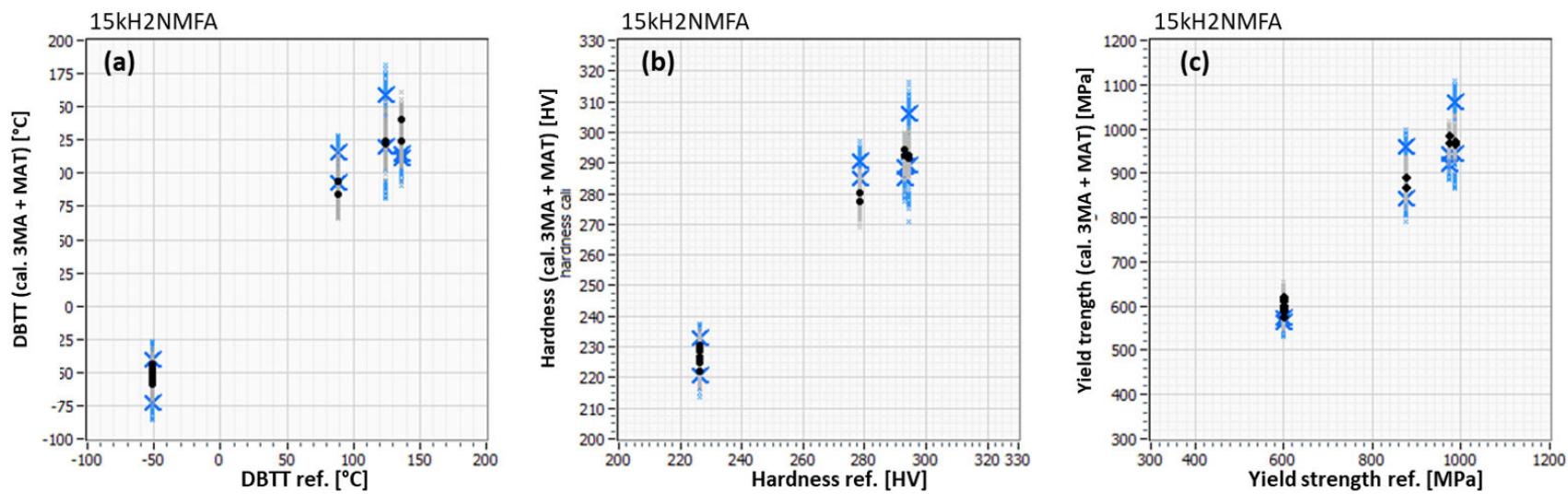

Figure 18. Results of the calibration procedure to predict DBTT (a), mechanical hardness (b), and yield strength (c) for 15Kh2NMFA.

Tables 5 and 6 show the correlation coefficients $\left(R^{2}\right)$ and root mean square errors (RMSEs) for the estimation of all targeted quantities: DBTT, hardness, and yield strength. All targeted quantities were estimated with an accuracy higher than $91 \%$, demonstrating the suitability of this procedure to estimate target quantities in a nondestructive manner. 
Table 5. Correlation coefficients $\left(\mathrm{R}^{2}\right)$ and root mean square errors (RMSEs) for the estimation of DBTT, mechanical hardness, and yield strength of A508 Cl.2 material.

\begin{tabular}{ccccc}
\hline Parameter & \multicolumn{2}{c}{$\mathbf{R}^{2}$} & \multicolumn{2}{c}{ RMSE } \\
\hline & Training & Test & Training & Test \\
\hline DBTT & $99.8 \%$ & $97.5 \%$ & $2.9{ }^{\circ} \mathrm{C}$ & $12.5^{\circ} \mathrm{C}$ \\
\hline Yield strength & $99.9 \%$ & $94.5 \%$ & $6.2 \mathrm{MPa}$ & $38.0 \mathrm{MPa}$ \\
\hline Hardness & $99.9 \%$ & $96.4 \%$ & $1.1 \mathrm{HV}$ & $6.6 \mathrm{HV}$ \\
\hline
\end{tabular}

Table 6. Correlation coefficients and root mean square errors for the estimation of DBTT, mechanical hardness, and yield strength of 15Kh2NMFA material.

\begin{tabular}{ccccc}
\hline Parameter & \multicolumn{2}{c}{$\mathbf{R}^{2}$} & \multicolumn{2}{c}{ RMSE } \\
\hline Training & Test & Training & Test \\
\hline DBTT & $99.6 \%$ & $92.5 \%$ & $5.2{ }^{\circ} \mathrm{C}$ & $21.4{ }^{\circ} \mathrm{C}$ \\
\hline Yield strength & $99.4 \%$ & $91.5 \%$ & $13.2 \mathrm{MPa}$ & $51.6 \mathrm{MPa}$ \\
\hline Hardness & $99.5 \%$ & $92.8 \%$ & $2.1 \mathrm{HV}$ & $7.9 \mathrm{HV}$ \\
\hline
\end{tabular}

\section{Discussion}

In this study, several material properties were determined through mechanical tests and micromagnetic examinations. Changes in mechanical properties are caused by neutronirradiation-induced microstructure defects, which, in turn, influence the magnetic properties measured using micromagnetic measurements.

It is well-known that an increase in neutron fluence yields an increase in the density and diameter of microstructure defects. The nature of the microstructure defects and of the degradation mechanism caused by neutron irradiation in RPV steels is dependent on, among other parameters (irradiation fluence, irradiation temperature), the chemical composition of the RPV steel, especially the $\mathrm{Cu}, \mathrm{Ni}$, and $\mathrm{P}$ contents. There are three important neutron-irradiation-induced damage mechanisms caused by matrix features, $\mathrm{Cu}$-rich precipitates and $\mathrm{Mn}-\mathrm{Ni}-\mathrm{Si}$-precipitates. The first one is responsible for hardening in both RPV steels, having $\mathrm{Cu}$ content below and above $0.04 \mathrm{wt} \%$, generally at low fluences. The second one occurs at high fluences in RPV steels with $\mathrm{Cu}$ content higher than $0.04 \mathrm{wt} \%$. The third one is typical for low-Cu RPV steels at high fluences [31]. In this study, the Cu contents of both RPV steels were higher than $0.04 \mathrm{wt} \%$ (Tables 1 and 2). Thus, for both RPV steels, the neutron-irradiation-induced embrittlement could be caused by matrix features at low fluence and $\mathrm{Cu}$-rich precipitates at high fluences. However, microstructural examinations (e.g., small neutron angle scattering and high-resolution transmission electron microscopy) were not performed in this study.

For both materials, we observed that neutron irradiation at low fluences caused a significant modification in material properties: hardness, embrittlement (DBTT), and yield strength. A further increase in neutron fluence caused a much smaller further degradation of the mechanical properties, whereas a further increase in the neutron fluence did not cause any further change in the mechanical properties, indicating saturation that was observed (Tables 3 and 4). For 15Kh2NMFA steel, a small decrease in DBTT was observed at high neutron fluence, but it remained within the uncertainties of such measurements. All these material properties and their progress, induced by neutron irradiation, are strongly influenced by neutron-irradiation-induced microstructure changes.

Microstructure defects impede dislocation movement and Bloch-wall movement and cause changes in mechanical and magnetic properties, respectively. Micromagnetic parameters depend on Bloch-wall movement during magnetization and characterize their interaction with microstructure defects such as precipitates, voids, dislocations, or grain boundaries. Coercivity proportionally depends on the interaction intensity between Bloch walls and microstructure defects. Kersten's and Dijkstra and Wert's theories describe the 
correlation between coercivity, volume, and diameter of small microstructure defects [32]. All these theories describe an increase in magnetic hardness with the rising volume and diameter of microstructure defects. Since all other micromagnetic parameters strongly correlate with coercivity, they similarly depend on the microstructure defects' diameter and volume.

The clear difference in the results of magnetic measurements between the nonirradiated and irradiated conditions correlates well with the results of the mechanical tests and can be explained by the occurrence of microstructure defects due to neutron irradiation (matrix features at low fluence and $\mathrm{Cu}$-rich precipitates at high fluence). Small microstructure defects impede Bloch-wall movement due to the foreign body effect and, therefore, cause an increase in magnetic hardness, as illustrated by the magnetic parameters in Figures 13-16. The foreign body effects describe the interaction between Bloch walls and small microstructure defects [31]. The higher the volume of small microstructure defects (matrix features), the higher the mechanical properties and the stronger the foreign body effect. The smaller change in mechanical properties at increased neutron fluence can be explained by an increase in the microstructure defects' (Cu-rich precipitates) diameter and a smaller increase of the volume of defects, which, in turn, similarly influence the magnetic properties. The foreign body effect and the interaction between Bloch walls and microstructure defects both weaken; thus, magnetic properties increase more slowly.

For the irradiated eastern RPV steel 15Kh2NMFA, we observed that parameters derived from both magnetic methods reached saturation. For western RPV material A508 C1.2, the MAT descriptor continuously increased, but most 3MA-X8 parameters reached saturation.

Another conclusion is that by applying different nondestructive magnetic techniques, a similar correlation was found between mechanical properties and the modification of magnetic parameters. This finding is encouraging for future practical applications of magnetic NDE.

The innovative part of this study is the combination of the results obtained using both magnetic methods, followed by a training procedure to determine targeted material properties (hardness, DBTT, and yield strength). Excellent correlation coefficients and impressively low RMSEs were achieved for the prediction and quantification of hardness, ductile to brittle transition temperature, and yield strength of the tested specimens (Figures 17 and 18). Correlation coefficients larger than $91 \%$ were obtained between nondestructively predicted and destructively determined mechanical properties (Tables 5 and 6). Therefore, the two magnetic methods resulted in a strong correlation between their outcomes, and their combination can be used to precisely predict different mechanical properties.

\section{Conclusions}

Changes in mechanical properties due to irradiation of standard surveillance Charpy specimens have often been published according to standard surveillance programs [1].

As experimentally observed, the relationship between neutron fluence and the micromagnetic parameters is nonlinear since the dependence of the mechanical properties on neutron fluence is nonlinear as well. The results of the individual micromagnetic measurements, performed following MAT and 3MA-X8 methods, prove their suitability for characterizing the progressive degradation of RPV steels caused by simulated operation conditions in terms of low-temperature neutron irradiation. Differences between individual specimens at the same irradiation condition or the same damage stage (same DBTT, yield strength, or hardness) affect the outcome of both kinds of measurements.

The combination of both magnetic methods allows for the prediction of mechanical properties with high accuracy, independent of the microstructural differences between individual specimens at the same irradiation condition. 
Author Contributions: Conceptualization, M.R. and A.G.; methodology, A.G., G.V., K.S., and I.S.; investigation, M.K., A.G., G.V., I.U., and I.S.; project administration, M.R. and A.G.; funding acquisition, M.R. and A.G. All authors have read and agreed to the published version of the manuscript.

Funding: This research was carried out within the frame of the "NOMAD" project. This project (Nondestructive Evaluation System for the Inspection of Operation-Induced Material Degradation in Nuclear Power Plants) has received funding from the Euratom research and training program 2014-2018 under grant agreement No. 755330.

Institutional Review Board Statement: Not applicable.

Informed Consent Statement: Not applicable.

Data Availability Statement: The data are contained within the article.

Conflicts of Interest: The authors declare no conflict of interest.

\section{References}

1. Ferreño, D.; Gorrochategui, I.; Gutiérrez-Solana, F. Degradation due to neutron embrittlement of nuclear vessel steels: A critical review about the current experimental and analytical techniques to characterise the material, with particular emphasis on alternative methodologies. In Nuclear Power-Control, Reliability and Human Factors; Tsvetkov, P., Ed.; IntechOpen Limited: London, UK, 2011; ISBN 978-9-53307-599-0. Available online: http:/ / www.intechopen.com/articles/show/title/non-destructivetesting-for-ageing-management-of-nuclear-power-components (accessed on 14 May 2020).

2. Niffenegger, M.; Leber, H.J. Monitoring the embrittlement of reactor pressure vessel steels by using the Seebeck coefficient. J. Nucl. Mater. 2009, 389, 62. [CrossRef]

3. Niffenegger, M.; Reichlin, K.; Kalkhof, D. Application of the Seebeck effect for monitoring of neutron embrittlement and low-cycle fatigue in nuclear reactor steel. Nucl. Eng. Des. 2005, 235, 1777-1788. [CrossRef]

4. Seiler, G. Early detection of fatigue at elevated temperature in austenitic steel using electromagnetic ultrasound transducers. In Proceedings of the Seventh International Conference on Low Cycle Fatigue: LCF7, Deutscher Verband für Materialforschung und-Prüfung e.V. (DVM), Aachen, Germany, 9-11 September 2013; pp. S359-S364.

5. Smith, R.L.; Rusbridge, K.L.; Reynolds, W.N.; Hudson, B. Ultrasonic attenuation, microstructure and ductile to brittle transition temperature in Fe-C alloys. Mater. Eval. 1993, 41, 219-222.

6. Dobmann, G.; Kröning, M.; Theiner, W.; Willems, H.; Fiedler, U. Nondestructive characterization of materials (ultrasonic and magnetic techniques) for strength and toughness prediction and the detection early creep damage. Nucl. Eng. Des. 1995, 157, 137-158. [CrossRef]

7. Jiles, D.C. Magnetic methods in nondestructive testing. In Encyclopedia of Materials Science and Technology; Buschow, K.H.J., Ed.; Elsevier Press: Oxford, UK, 2001; p. 6021.

8. Blitz, J. Electrical and Magnetic Methods of Nondestructive Testing; Adam Hilger IOP Publishing, Ltd.: Bristol, UK, 1991.

9. Lo, C.C.H.; Jakubovics, J.P.; Scrub, C.B. Non-destructive evaluation of spheroidized steel using magnetoacoustic and Barkhausen emission. IEEE Trans. Magn. 1997, 33, 4035-4037. [CrossRef]

10. Kikuchi, H.; Ara, K.; Kamada, Y.; Kobayashi, S. Effect of microstructure changes on Barkhausen noise properties and hysteresis loop in cold rolled low carbon steel. IEEE Trans. Magn. 2009, 45, 2744-2747. [CrossRef]

11. Hartmann, K.; Moses, A.J.; Meydan, T. A system for measurement of AC Barkhausen noise in electrical steels. J. Magn. Magn. Mater. 2003, 254-255, 318-320. [CrossRef]

12. Pirfo Barroso, S.; Horváth, M.; Horváth, Á. Magnetic measurements for evaluation of radiation damage on nuclear reactor materials. Nucl. Eng. Des. 2010, 240, 722-725. [CrossRef]

13. Augustyniak, B.; Chmielewski, M.; Piotrowski, L.; Kowalewski, Z. Comparison of properties of magnetoacoustic emission and mechanical barkhausen effects for P91 steel after plastic flow and creep. IEEE Trans. Magn. 2008, 44, 3273-3276. [CrossRef]

14. Devine, M.K. Magnetic detection of material properties. J. Min. Met. Mater. JOM 1992, 44, 24-30. [CrossRef]

15. Kronmüller, H.; Fähnle, M. Micromagnetism and the Microstructure of Ferromagnetic Solids; Cambridge University Press: Cambridge, UK, 2003.

16. Szielasko, K.; Tschuncky, R.; Rabung, M.; Seiler, G.; Altpeter, I.; Dobmann, G.; Herrmann, H.G.; Boller, C. Early Detection of Critical Material Degradation by Means of Electromagnetic Multi-Parametric NDE. AIP Conf. Proc. 2014, 1581. [CrossRef]

17. Dobmann, G.; Altpeter, I.; Kopp, M.; Rabung, M.; Hubschen, G. ND-materials characterization of neutron induced embrittlement in German nuclear reactor pressure vessel material by micromagnetic NDT techniques. In Electromagnetic Nondestructive Evaluation (XI); IOS Press: Amsterdam, The Netherlands, 2008; p. 54. ISBN 978-1-58603-896-0.

18. Altpeter, I.; Becker, R.G.; Dobmann, R.; Kern, W.A.; Theiner, A. Yashan: Robust Solutions of Inverse Problems in Eletromagnetic Non-Destructive Evaluation. Inverse Probl. 2002, 18, 1907-1921. [CrossRef]

19. Szielasko, K.; Wolter, B.; Tschuncky, R.; Youssef, S. Micromagnetic materials characterization using maschin learning—Progress in Nondestructive Prediction of Mechanical Properties of Steel and Iron. Tech. Mess. 2020, 87, 428-437. [CrossRef] 
20. Takahashi, S.; Kobayashi, S.; Kikuchi, H.; Kamada, Y. Relationship between mechanical and magnetic properties in cold rolled low carbon steel. J. Appl. Phys. 2006, 100, 113908. [CrossRef]

21. Kobayashi, S.; Gillemot, F.; Horváth, Á.; Székely, R. Magnetic properties of a highly neutron-irradiated nuclear reactor pressure vessel steel. J. Nucl. Mater. 2012, 421, 112-116. [CrossRef]

22. Tomáš, I. Non-destructive Magnetic Adaptive Testing of ferromagnetic materials. J. Mag. Mag. Mat. 2004, 268, 178-185. [CrossRef]

23. Tomáš, I.; Vértesy, G. Magnetic Adaptive Testing. In Nondestructive Testing Methods and New Applications; Omar, M., Ed.; IntechOpen Limited: London, UK, 2012; Available online: http://www.intechopen.com/articles/show/title/magnetic-adaptivetesting (accessed on 8 November 2020)ISBN 978-953-51-0108-6.

24. Tomáš, I.; Vértesy, G.; Pirfo Barroso, S.; Kobayashi, S. Comparison of four NDT methods for indication of reactor steel degradation by high fluences of neutron irradiation. Nucl. Eng. Des. 2013, 265, 201-209. [CrossRef]

25. Uytdenhouwen, I.; Chaouadi, R.; Other NOMAD Consortium Members. NOMAD: Non-destructive Evaluation (NDE) system for the inspection of operation-induced material degradation in nuclear power plants-Overview of the neutron irradiation campaigns. In ASME 2020 Pressure Vessels E Piping Conference; Non-Destructive Examination, V007T07A003, PVP2020-21512; ASME: New York, NY, USA, 2020; Volume 7.

26. Uytdenhouwen, I.; Chaouadi, R. Effect of neutron irradiation on the mechanical properties of an A508 Cl.2 forging irradiated in a BAMI capsule. In Pressure Vessels and Piping Conference; Codes and Standards, V001T01A060, PVP2020-21513; ASME: New York, NY, USA, 2020; Volume 1.

27. Uytdenhouwen, I.; Chaouadi, R. Accepted to be Published in the ASME 2021 Proceedings PVP2021-61969 Paper: Effect of Neutron Irradiation on the Mechanical Properties of an A508 Cl.2 and 15Kh2NMFA Irradiated in the NOMAD_3 rig in the BR2 Cooling Water. Available online: https:/ / proceedings.asmedigitalcollection.asme.org/PVP/ (accessed on 2 March 2021).

28. Tomáš, I.; Perevertov, O. Permeameter for Preisach approach to materials testing. In JSAEM Studies in Applied Electromagnetics and Mechanics, 9th ed.; Takagi, T., Ueasaka, M., Eds.; IOS Press: Amsterdam, The Netherlands, 2001; pp. 5-15.

29. Vértesy, G.; Gasparics, A.; Uytdenhouwen, I.; Szenthe, I.; Gillemot, F.; Chaouadi, R. Nondestructive investigation of neutron irradiation generated structural changes of reactor steel material by magnetic hysteresis method. Metals 2009, 10, 642. [CrossRef]

30. Vértesy, G.; Gasparics, A.; Griffin, J.M.; Mathew, J.; Fitzpatrick, M.E.; Uytdenhouwen, I. Analysis of surface roughness influence in non-destructive magnetic measurements applied to reactor pressure vessel steels. Appl. Sci. 2020, 10, 8938. [CrossRef]

31. Integrity of Reactor Pressure Vessels in Nuclear Power Plants: Assessment of Irradiation Embrittlement Effects in Reactor Pressure Vessel Steels; IAEA Nuclear Energy Series No.NP-T-3.11; Atomic Energy Agency: Vienna, Austria, 2009.

32. Seeger, A. Moderne Probleme der Metallphysik; Springer: Berlin/Heidelberg, Germany, 1966; p. 232. 